\title{
1 Risk factors for the occurrence of sexual misconduct during archaeological
}

2 and anthropological fieldwork

4 Danielle J Bradford ${ }^{1} *$ \& Enrico R Crema ${ }^{2}$

51 Unaffiliated scholar

62 Department of Archaeology, University of Cambridge, Downing Street, CB2 3ER

7 Cambridge, UK

$8 *$ Corresponding Author: djb24272@gmail.com

\section{Abstract}

Fieldwork is crucial to advancing knowledge in archaeology and anthropology, but

14 during fieldwork. Going forward, fieldwork must be made safe and inclusive. To achieve

15 this, we must understand why sexual misconduct takes place during fieldwork.

We surveyed an international sample of archaeologists and anthropologists $(n=300)$

18 about their most recent fieldwork experience. We examine evidence for risk factors

19 predicting sexual misconduct on field sites, and our findings suggest that length of fieldwork,

20 presence and communication of policies and protocols, and the gender and sexuality of the

21 individual, are all significant. In particular, we find evidence for increased risk to non-male

22 and non-heterosexual individuals. We also gathered qualitative evidence from our

23 respondents, who reported that in some cases, they were discouraged from reporting and

24 faced retaliation, they were dissatisfied with the handling of complaints, and field site

25 policies and protocols were not consistently or effectively implemented.

Fieldwork can be a high-risk environment for marginalized individuals to experience

29 risk environment for perpetrators in terms of consequences. To make fieldwork a safe

30 environment for all, policies and protocols that mitigate the risk of sexual misconduct must

31 be consistently implemented, and properly communicated. 


\section{Introduction}

Academic fieldwork is a vital area of knowledge production in many disciplines, and it is of particular importance in archaeology and anthropology (Moser 2007). It is also a primary workplace for many researchers (Nelson, Rutherford, Hinde and Clancy 2017). Fieldwork acts as a rite of passage for Early Career Researchers and young aspiring researchers entering into the discipline (Moser 2007; Langham 1981). However, it is also an environment which presents its own unique risks - from travelling to and working in areas of political unrest, harsh climates, differing cultures (Moser 2007), or the threat of sexual violence — both from colleagues and from individuals outside of the research team (Clancy, Nelson, Rutherford and Hinde 2014; Meyers et al 2018; Voss 2021a).

This paper focuses specifically on the threat of sexual misconduct during archaeological and anthropological fieldwork. We operationally define the term fieldwork to encompass any academic work that occurs outside of a home institution. This also includes commercial archaeology, for whom the field may also be their main workplace. Fieldwork is extremely diverse, even within archaeology and anthropology. Some may be situated in a formal fieldschool, with senior professionals and students alike living together in dormitory-style accommodation. Others may involve a researcher working at their field site alone, sometimes also living alone or at other times living with informants or their families. Fieldwork also varies in both location and length. Importantly, different variations of fieldwork are likely to have different implications for the occurrence of sexual misconduct. For example, if a participant is part of a fieldschool and largely interacting with colleagues, it stands to reason that they would be more likely to experience sexual misconduct from a colleague than a lone researcher would be. This also has various implications for the power dynamics at the fieldsite. A lone researcher may in some ways hold power over their informants, especially if they are providing monetary or material incentives for being part of the research. On the other hand, informants may hold power over the lone researcher, as they may have information or contacts vital to their research, or may be in control of their accommodation. 

of a community archaeology project in Scotland involving volunteers (@) Oliver et al 2016; used with permission). Panel B: An anthropologist at a robotics company in North America, where she visited for 3 weeks collecting ethnographic data (ㅇ Chun and Knight 2020; used with permission). Panel C: An anthropologist planting rice at their fieldsite (@ Liana Chua; used with permission). Panel D: An anthropologist on horseback during fieldwork in Mongolia, 1999 (@ Christopher Kaplonski; used with permission). Panel E: An anthropologist eating with members of the local community during a ritual (@) Liana Chua; used with permission). Panel F: A photo taken by an anthropologist at a Kichwa discourse

Whilst at any given time and in any given context individuals will be at some risk of experiencing sexual violence, previous work (e.g. Alriksson-Schmidt, Armour and Thibadeau, 2010; Berdahl and Moore 2006; Cantalupo 2019; Chamberlain et al 2008; Clancy, Nelson, contest in Tena (@) Wroblewski 2019; used with permission).

0 Rutherford and Hinde 2014; McCann 2005; Meyers et al 2018) focusing on the prevention of violence have highlighted that different groups of individuals may be at more risk than others depending on their demographic characteristics. Similarly, work has found some contexts to be higher risk than others, such as in the military, academia (Ilies, Hauserman, Schwochau and Stibal 2003), and low-wage professions such as accommodation and food services and retail (Frye 2017). Within fields certain job roles can also be higher risk; a report by the US Department of the Interior found that seasonal colleagues were more likely to experience sexual assault related behaviours (Department of the Interior, 2017). Therefore, certain groups of individuals and/or certain contexts may "require special consideration in violence prevention endeavors" (AlrikssonSchmidt, Armour and Thibadeau, 2010, 362). In this paper we use relative risk as a framework to identify certain risk-factor that may increase, or decrease, the risk an individual faces of experiencing sexual misconduct within archaeological and anthropological fieldwork. Many have written about experiencing sexual harassment and assault during fieldwork (e.g. Kloß 2016; Pollard 2009; Sharp and Kremer 2006; Voss 2021a). Recent studies using survey 
data have reported high rates of experiencing some form of sexual misconduct during academic fieldwork, with 64\% ( $n=658$; Clancy, Nelson, Rutherford and Hinde 2014) and 68\% ( $n=244$;

89 Meyers et al 2018) of participants from these studies having experienced misconduct respectively.

90 Both studies also found that women reported these experiences at higher rates, with women 3

91 (Clancy et al 2014) to 3.5 times (Meyers et al 2018) more likely to report experiencing sexual 92 harassment.

However, the quantitative study of sexual misconduct during fieldwork is still in its

94 infancy, and there are vast gaps in our knowledge about these environments and the human 95 interactions within them. Quantitative studies so far, for example, have been unable to sufficiently 96 speak to the experiences of LGBTQ+ researchers, who are typically under-represented in the 97 samples analysed so far. Furthermore, to the best of our knowledge, no study has yet tried to use 98 data to explain why the rates of misconduct seem to be so high in fieldwork, nor to identify any specific risk-factors that may account for this. The latter is particularly important when

100 considering how to ensure our colleagues and students are safe to undertake fieldwork: if we do 101 not understand the risk, we cannot effectively mitigate it.

102 Here, we quantitatively assess the specific risk factors within archaeological and 103 anthropological fieldwork that may predict the occurrence of sexual misconduct in order to 104 address this gap. Our study seeks to determine how, and whether, a number of measured variables 105 affects the probability of someone experiencing sexual misconduct during fieldwork. In 106 particular, we infer the effects of the length of fieldwork and the nature of the policies and 107 protocols implemented for that field site. Furthermore, numerous studies have previously found 108 that individuals part of traditionally marginalised groups, such as being LGBTQ+, disabled, 109 gender non-conforming, a woman, or an ethnic minority, are more likely to have experienced 110 sexual harassment or assault (Berdahl and Moore 2006; Cantalupo 2019; Chamberlain et al 2008;

111 Clancy, Nelson, Rutherford and Hinde 2014; Department of the Interior 2017; McCann 2005;

112 Meyers et al 2018; National Park Service 2017; National Union of Students 2018; Voss 2021a; 113 Voss 2021b). Thus, we also measure and test the effects of gender, sexuality, disability status and 114 of being an ethnic minority against the likelihood of having experienced sexual misconduct. 


\section{Materials and Methods}

\section{Online survey}

117 We obtained ethical approval from the Ethics Committee for School of the Humanities and

118 Social Sciences, University of Cambridge. We obtained informed consent from participants through

119 the Participant Information Sheet displayed prior to commencement of the survey, and by an initial set

120 of questions proceeding the main part of the survey confirming the potential participant's

121 understanding and consent (Supplementary materials 2).

122 We used an online survey for data collection in line with previous research (Clancy, Nelson,

123 Rutherford and Hinde 2014; Meyers et al 2018; National Union of Students 2018). The survey was

124 divided into three main sections: questions regarding the demographic information of the participant,

125 questions regarding their most recent fieldwork experience, and - if they had ever experienced sexual

126 misconduct in the workplace - questions regarding their most recent experience of this (See

127 Supplementary materials 2 for full survey). There was a final section with an open box question in

128 order to obtain additional qualitative data.

129 In order to gather data regarding potential experiences of sexual misconduct we presented a

130 series of scenarios that fall under the UK legal definitions of sexual harassment (Citizens Advice n.d.

131 a) and assault (Citizens Advice n.d. b) and asked whether or not the participant had personally

132 experienced any of these during their most recent fieldwork experience (Variable "Frequency", Table

133 1). This allowed for participants to report sexual harassment and/or assault without having to label

134 their experiences. Even if an individual has experienced an event that falls under the legal definitions

135 of harassment or assault, they may not be able to or want to label it as such due to factors such as

136 societal stigma, fear, and a culture of victim-blaming (McDonald 2011). Individuals may either under

137 or over interpret the seriousness of the events they've experienced. Listing experiences in such a way

138 allows for an objective assessment of events.

139 The survey consisted of a total of 65 questions. However, the number of questions

140 participants answered varied depending on what answers they gave. For example, if they had never

141 experienced sexual misconduct in the workplace or fieldwork, the survey would automatically skip 
142 the sections asking questions on this. All questions were also optional. The sample size for each

143 question is presented below with the results.

144 The survey was open to all current or former archaeologists and anthropologists

145 internationally who had carried out fieldwork-based research. We distributed the survey using a

146 snowball sampling technique via social media platforms and via emails sent and forwarded to contacts

147 in different universities and institutions.

148 We received 300 responses to the online survey. Of these 300 participants, $58.7 \%$ were

149 female $(n=176), 23.7 \%$ were male $(n=71)$, and $1 \%$ were non-binary $(n=3)$. There were also a diverse

150 range of sexualities: $56 \%$ identified as heterosexual $(n=168), 3.33 \%$ as homosexual $(n=10), 19.7 \%$ as

151 bisexual $(\mathrm{n}=59)$, and $1.67 \%$ as asexual $(\mathrm{n}=5)$. We had participants from 26 countries across six

152 continents. Participants possessed a range of education levels at the time of their last fieldwork

153 experience, ranging from high school and A-Level (6.67\%, $\mathrm{n}=20)$, to PhDs (16.33\%, n=49).

154

\section{Variables and Data Processing}

The length of fieldwork (Variable "Length", Table 1), was treated as an ordinal variable by

157 replacing each level with sequential integers ${ }^{1}$. For example, ' $<1$ week' became ' 1 ', ‘ $>1$ week -1

158 month' became '2', and so on. Those who answered 'Other (please specify)' for the variable of

159 sexuality were manually coded into one of the listed categories if appropriate (Variable "Sexuality",

160 Table 1). If the answer given did not obviously fit into one of the categories it was excluded from the

161 data analysis. For demographic questions we excluded data from those who answered 'Prefer not to

162 say' or who did not provide any answer. For gender (Variable "Gender", Table 1), we combined the

163 data from those who answered female or non-binary and compared these against male participants.

164 Finally, the variable sexuality was treated as binary by grouping responses into 'sexuality minority'

165 and 'heterosexual'.

166 In order to identify themes from the open box responses, we assigned initial codes to

167 responses, reviewed these codes (following Birks and Chapman 2008) and developed a final set of

\footnotetext{
${ }^{1}$ Treating length as numeric values by taking the mid-point of each category (e.g. <1 week became 3.5 days, and $>1$ week -1 month became 17.5 days) did not qualitatively impact on the results,
} 
168 codes based on emergent themes (Stewart and Shamdasani 2014). To code the initial responses we

169 went through each response individually and summarised it with a couple key words. We then coded

170 these into the emergent themes: policies and protocols, alcohol, and issues with reporting incidences

171 of sexual misconduct. This was done by identifying key words. For example, if the text contained the

172 words 'alcohol', 'alcoholic', 'drinking culture', 'drunk', or 'drunkenness' it was coded into the theme

173 'alcohol'. If the text contained the words 'policy' or 'protocol' or 'rules', it was coded into 'policy

174 and protocols'. If the text said that the participant had not reported, had reported and felt it was

175 handled poorly, or had been discouraged from reporting, this was coded into 'Issues with reporting'.

\section{Statistical Analysis}

All statistical analysis was carried out using R version 4.0.2 (R Core Team 2019).

We performed multiple Chi-square tests to compare gender, sexuality, disability, and ethnic

180 minority identity respectively against the frequency of those who experienced sexual harassment or

181 assault during their most recent fieldwork experience.

182
Table 1. Table showing the variables used in the GLM, with the survey questions the variable came from, the raw categories, and the coded categories.

We fitted a binomial generalised linear model (GLM) on the hypothesised predictor variables

(Table 1), to determine if these variables impacted on whether the participant had reported experiencing sexual misconduct during their most recent fieldwork experience or not. We then extracted and compared odds ratios and made counterfactual plots to examine the potential impact of these variables on the likelihood of sexual misconduct having occurred. Our model was as follows: 


\section{Results}

194 Who is most at risk on site?

Non-male participants were significantly more likely to have experienced sexual misconduct

196 during fieldwork (chi-square test, $\chi 2=7.54, \mathrm{p}=0.006028, \mathrm{df}=1$ ), as were sexual minority individuals

197 (chi-square test, $\chi 2=7.01, \mathrm{p}=0.008099, \mathrm{df}=1$ ). Statistical tests failed to reveal significant differences

198 between disabled and non-disabled participants (chi-square test, $\chi^{2}=1.67, \mathrm{p}=0.1959, \mathrm{df}=1$ ), nor

199 between those who identified as an ethnic minority and those who did not (chi-square test, $\chi 2=$

$200 \quad 0.0605, \mathrm{p}=0.8057, \mathrm{df}=1)$.

201

202 Can we predict sexual misconduct on site?

\section{Model 1}

\begin{tabular}{lccc}
\cline { 2 - 4 } Field site variables & Beta & Standard Error & Odds Ratio \\
\hline Policies in place and communicated & $-4.27 * * *$ & 0.76 & 0.01
\end{tabular}

(APP)

$\begin{array}{llll}\text { Policies in place but not communicated } & 1.94 * & 0.77 & 6.96\end{array}$

prior to commencement of fieldwork

(FO)

$\begin{array}{lccc}\text { No known policies (DNK) } & 1.26 * & 0.56 & 3.52 \\ \text { No policies in place (NIP) } & 2.45 * * * & 0.58 & 11.57 \\ \text { Length of fieldwork } & 0.26 * & 0.13 & 1.30 \\ \text { Gender: Non-Male } & 0.79 & 0.47 & 2.19 \\ \text { Sexuality: Sexual minority } & 1.22 * * & 0.40 & 3.39\end{array}$

203 Table 2. Summary statistics for Model 1.

$204 * \mathrm{p}<.05$

$205 * * \mathrm{p}<.01$

$206 * * * \mathrm{p}<.001$

207

208 
Figure 2. Plot showing odd ratios and confidence intervals on the $x$-axis and the different site policies, length of fieldwork, and gender and sexuality of participants on the y-axis.

Figure 3. Counter-factual plot showing model prediction for sexual misconduct.

214 The results presented in Table 2 and Figure 2 indicate that longer periods of fieldwork predict

215 a higher likelihood of experiencing sexual misconduct $(\beta=0.2628, p=0.03670$, Figure 2). Sites with

216 no policies or protocols in place specifically regarding sexual misconduct also predicted a higher

217 likelihood of experiencing sexual misconduct $(\beta=2.4487, \mathrm{p}=2.82 \mathrm{e}-05$, Figure 2$)$. The probability

218 that participants would experience sexual misconduct during fieldwork was significantly decreased

219 when the participant knew of policies and protocols before arriving on site (APP; $\beta=-4.2681, \mathrm{p}=$

$2202.29 \mathrm{e}-08$, Figure 2). For example, the model predicts that the probability of experiencing sexual

221 misconduct for a non-male, sexual minority participant in fieldwork with a duration between 6 months

222 to one year is $82 \%$ (95\% CI: 62 93\%) with no policies in place (NIP). However, this drops to $28 \%$

223 (95\% CI: 11 55\%) when policies are in place and communicated prior to the commencement of the

224 fieldwork (Figure 3). In fact, the model predicts that the probability of sexual misconduct is lower for

225 a participant who is in the field for longer than a year when policies are in place and communicated

226 than for a fieldworker only in the field for less than a week at a site where there are no policies in

227 place (Figure 3).

Out of all measured variables, and with all things being equal, participants attending a

229 fieldsite where there were no policies or protocols in place were the most at risk of having

230 experienced sexual harassment or assault (OR 11.573, Figure 2). Sexual minority participants (OR

231 3.391, Figure 2) and non-male participants (OR 2.194, Figure 2) had increased probabilities of

232 experiencing sexual misconduct on site; being part of a sexual minority had a larger effect than being

233 non-male and was statistically significant, whereas being non-male was not. Similarly to length,

234 policies can mitigate the increased risk to non-male and sexual minority participants. For example, a

235 non-male, sexual minority participating in fieldwork for the duration of between 1 week to 1 month 
236 has a $15 \%$ (95\% CI 6 34\%) probability of experiencing sexual harassment when policies are in place

237 and communicated. In comparison, the probability for a heterosexual male participant undertaking

238 fieldwork for the same amount of time but with no policies in place is 22\% (95\% CI: 9 43\%) (Figure

239 3).

241 Open box responses.

242 Sixty-Seven participants replied to the open-box question. $16.42 \%(n=11)$ of these spoke of

243 difficulties with reporting incidences, from being discouraged from and retaliated against for

244 reporting, to being generally dissatisfied with the ways in which reports were handled. From other

245 survey questions, we found that $65 \%(n=13 / 20)$ of participants who reported their experiences did not

246 feel their report was handled with sensitivity, nor that the result of the report was proportionate to the

247 events. The open-box responses also identified that concerns about a 'culture' of heavy drinking was a

248 common concern for safety on field sites, with $7.46 \%(n=5)$ of participants who answered the open-

249 box question noting this as a concern.

250 


\section{Discussion}

\section{Study Limitations}

Using a snowball sampling method to access potential participants can lead to potential biases

254 (Biernacki and Waldorf 1981). However, selecting a random subset of archaeologists and

255 anthropologists internationally to partake in the survey posed various ethical difficulties due to the

256 sensitive nature of the research. Similarly, in order to preserve participant anonymity we did not carry

257 out individual interviews with participants, which limited the quality of qualitative data that we were

258 able to collect. In order to try and mitigate against the risk of self-section bias (that is, the chance that

259 a potential participant may be more likely to take part in a study about sexual violence if they have

260 experienced it) we avoided mentioning sexual misconduct in the survey title and social media posts

261 (which was titled 'Fieldwork Experiences'). However, it had to be discussed on the Participant

262 Information Sheet to allow potential participants to make an informed decision as whether to partake

263 or not, and we could not control how others described the project and survey when they distributed it.

264 It is also important to note that previous studies (e.g. Rosenthal and Freyd 2018) have found no

265 evidence that studies regarding sexual violence are biased by self-selective recruitment

266 methodologies. Furthermore, as we were largely interested in risk-factors and not the frequency of

267 misconduct per se, we believe any potential impact of response bias on our results is minimal. We

268 also specifically asked participants about their most recent experience of fieldwork in order to

269 mitigate any bias towards the reporting of a particular experience; even if individuals who

270 experienced misconduct might have been more likely to take the survey, the assessment of the effects

271 of different risk-factor variables should be minimally biased as our data is based on their most recent

272 experiences. Finally, it is worth mentioning that the anonymous nature of the survey did not allow for

273 a control on sample independence, and given our sampling strategy there is undoubtedly the

274 possibility that respondents might have participated to the same fieldwork, potentially biasing our

275 outcome to some degree.

277 What factors increase the risk of sexual misconduct during fieldwork? 
The quantitative data presented here suggests a correlation between the occurrence of sexual

279 misconduct during fieldwork and both the length of the fieldwork and the policies and protocols

280 regarding sexual misconduct that were in place at the fieldwork site. This relationship is further

281 supported by the fact that participants directly linked a lack of specific and effective policies and

282 protocols as contributing to a culture which allows sexual misconduct to occur. One respondent wrote

283 that "Sometimes, the casual nature of fieldwork makes things confusing or might lead to unwanted

284 experiences. Especially without prior clarification of consent policy.”. Other participants wrote about

285 a perceived culture of having to 'put up' with sexual misconduct during fieldwork, one even going as

286 far as describing it as a "necessary evil of fieldwork". Similar findings have been reported in other

287 work contexts; both the US Department of the Interior (Department of the Interior 2017) and the US

288 National Park Service (National Park Service 2017) found that sexual harassment was more common

289 where there was a perception of tolerance for such behaviours.

In fieldwork, Nelson et al (2017) also found that absence of clear rules regarding appropriate

291 behavior on field sites to be associated with experiences of sexual harassment. Nelson et al also found

292 that sites with clear behavioural rules often clustered together with sites that enforced consequences

293 when these rules were broken, including consequences that removed the perpetrator from the field

294 site. In contrast, at sites where rules were either ambiguous or completely absent, consequences were

295 often unclear or also entirely absent. In some cases, perpetrators were allowed to continue to harass or

296 assault multiple victims continuously throughout the field season. It may be, therefore, that risk of

297 sexual misconduct decreases when rules are in place not just because it signals behavioural

298 expectations, but also because when rules are broken perpetrators are either removed or face

299 consequences harsh enough that they are prevented from going on to harass or assault multiple

300 victims.

301 The survey responses shows clearly that longer fieldwork duration is associated with a higher

302 likelihood of sexual misconduct occurrence. Clearly, a longer field season provides a larger window

303 for sexual misconduct, but it is also possible that at the start of a given fieldwork season participants

304 are likely to be acting responsibly and respectfully, especially if at the start of fieldwork policies

305 pertaining to behaviour, and perhaps even sexual misconduct specifically, were communicated to the 
306 participants. However, their ability to sustain that good behaviour may deteriorate over time,

307 particularly when considering how the other risk factors such as alcohol consumption and a culture of

308 tolerance of misconduct may act cumulatively over time, increasingly signalling to potential

309 perpetrators that this may be an environment in which sexual misconduct will have a low probability

310 of consequence. To ensure the anonymity of the participants we did not collect any information

311 regarding the timing of sexual misconduct nor the exact duration of the field season, so it was not

312 possible to evaluate this hypothesis.

313 A key outcome suggested by our analyses is the impact of how policies and protocols are

314 effectively communicated. While the existence of policies undoubtedly decreased the likelihood of

315 sexual misconduct, a major factor was whether participants knew about these policies and protocols

316 before arriving at the site. Interestingly, the risk of having experienced sexual misconduct during

317 fieldwork increased when there were policies in place, but the participant had only found out about

318 them after arriving on site. Participants who found out whilst on site were actually more at risk than

319 those who did not know of any policies in place. One possibility is that participants who find out

320 about the existence of policies and protocols whilst on site find out because they need to access them,

321 after already having experienced some form of sexual violence that they wish to report or access

322 support for.

323 Furthermore, the effect of field season length seems to be offset by the implementation of,

324 and participant knowledge of, policies and protocols regarding sexual misconduct. When individuals

325 knew of policies and protocols before arriving on site, the impact of the length of fieldwork as a risk-

326 factor decreased. In practice, this suggests that an individual partaking in fieldwork for a significant

327 period of time, in a context where there were no existing policies and protocols regarding sexual

328 misconduct in place, would be most at risk of experiencing sexual misconduct. However, if

329 individuals are aware of policies and protocols before arriving on site those carrying out fieldwork for

330 a year or more face less risk even than those participating in fieldwork for a much shorter period of

331 time in a context where there are no policies or procedures. It is important to stress that the mitigation

332 strategy for length of fieldwork as a risk factor for sexual misconduct should not be to prevent 
333 fieldwork from taking place, nor to shorten fieldwork. The risk of length can instead be significantly

334 mitigated by the implementation and communication of policies and protocols.

\section{Fieldwork: A low-risk environment for perpetrators?}

Our results show that fieldwork is a low-risk environment for perpetrators in regard to a lack

338 of consequences, and that this may facilitate sexual misconduct. Whilst there have been many theories

339 as to why sexual misconduct occurs, one common theme is the concept of a low-risk environment

340 (e,g, Hagen 1979; Symons 1979; Vandermassen 2011). If an individual views the risk of facing

341 consequences as low, they may be more likely to commit acts of sexual misconduct. Nelson et al

342 found that, in fieldwork, lack of clear rules and a lack of enforcement of rules clustered together with

343 experiences of sexual harassment and assault, as well as unfair gendered divisions of labour and a

344 “denial of access [...] to professional opportunities" (Nelson et al 2017, 714).

We found the site's policies and protocols to be a significant predictor for the occurrence of

346 sexual misconduct in fieldwork. Not only was there a significant increase in sexual misconduct when

347 the participant did not know about protocols and policies regarding sexual harassment for that site,

348 there was specifically a decrease in sexual misconduct when participants knew about the policies

349 before they arrived on site as opposed to finding out when they were there. In an environment where

350 colleagues are often living together for long periods of time and are socialising together as well as

351 working, policies and protocols are vital to signal a culture of zero-tolerance to sexual misconduct.

352 Furthermore, the need for policies and protocols and the mishandling of reports made during

353 fieldwork were two key themes identified from the open box responses. One participant spoke of a

354 "culture of shame and silence around sexual assault during fieldwork", and another speaks of

355 "laugh[ing] [incidences] off”, despite feeling uncomfortable. Another reports experiencing

356 inappropriate comments from an individual more senior than them, and says "I had no option but to

357 grit my teeth". Another participant reports being told to "rise above it". Twelve participants spoke

358 about no or inadequate action being taken in response to reports, actively being discouraged from

359 reporting, or feeling like they could not report without facing retaliation. 
Another factor we have identified in our survey that may contribute to fieldwork as being

361 perceived by perpetrators as an environment of 'low-risk' for consequences or resistance is a culture

362 of heavy drinking. Participants speak of high alcohol consumption as leaving junior participants

363 vulnerable. One participant wrote "A large part of archaeological culture which needs to change is

364 archaeologist [equals] alcoholic. [...] New, junior professional archaeologists tend to find themselves in intense situations fused with alcohol and they are not safe". Another wrote about their experiences

366 at multiple fieldsites, describing an "atmosphere of competitive camaraderie, meaning that bragging,

367 joking, and bringing up drinking and sex have been central aspects of the dig culture". Participants

368 also describe the "casual nature" of fieldwork as potentially leading to instances of sexual misconduct.

369 There is a perception that high levels of alcohol consumption leaves participants, especially junior

370 participants, vulnerable. This is particularly important when viewing drinking and informal socialising

371 as not merely a way of relaxing during non-working hours, but actually as a largely unspoken but

372 critical part of the profession. Leighton (2020) has named this performative informality, and states

373 that when a profession such as archaeology presents itself as "fun, open, friendly, and meritocratic"

374 (Leighton 2020, 445) those who do not or do not wish to act in this way (such as, in this case,

375 drinking heavily or engaging in competitive camaraderie) are viewed as less of an archaeologist, and

376 may suffer negative career consequences. This is especially critical when, as Leighton highlights,

377 professional opportunities "often stem from informal friendship-based contracts" (Ibid), which are

378 reserved to those who are willing to engage in this performative informality.

Furthermore, a number of participants referenced inappropriate comments merely being

380 perceived as "jokes", or "trench humour". One participant even spoke about an experience where,

381 whilst a man touched her without consent in the field in front of other participants, "instead of saying

382 anything, they [the bystanders] just laughed", indicating that in some cases it is not only inappropriate

383 comments that are perceived as jokes, but potential instances of assault also.

In a work environment that is also a social environment, and an environment in which alcohol

385 is frequently consumed, perpetrators may view this as a context in which they can exhibit

386 unacceptable and harmful behaviours and, within fieldwork, are able to pass it off as "trench 
387 humour". It also may be that there is a culture in fieldwork that condones this behaviour. This is

388 exemplified by the participant told to "rise above" instances of misconduct. This does not only apply

389 to perpetrators but also to witnesses and bystanders, enabling inappropriate behaviour to go

390 unchecked and unpunished, creating an environment for all in which there is an absence of

391 professionalism and respect for others.

392 It is clear that fieldwork is not the only environment in which sexual misconduct occurs, nor

393 the only environment in which inappropriate behaviour may be condoned or normalized. Leighton

394 (2020) describes performative informality as occurring both at home institutions and in the field. Voss

395 (2021a) wrote about their experiences of sexual misconduct in archaeology, both during fieldwork

396 and during lab and office work. The variables present in fieldwork that contribute to a culture in

397 which sexual misconduct is perceived as not only common but something one must rise above or put

398 up with are not unique to fieldwork, it may be that they just present more acutely in the field. This

399 may be at least due to the intensity of fieldwork, where participants are working and living together in

400 an often stressful environment. One participant references this explicitly, stating that "I reported the

401 issues [sexual misconduct] I was experiencing and was basically told it was my job to rise above it,

402 that these sorts of things happen in stressful contexts and that basically it could be expected".

403 We suggest that fieldwork is a low-risk environment for perpetrators in two main respects: 1)

404 it is an environment in which often working, socialising, and living all occur simultaneously and are

405 shared with other colleagues, and thus perpetrators may view it as a context in which professional

406 boundaries are blurred and the risk of consequences are low, and 2) the very policies and protocols

407 needed to address this are not consistently implemented and communicated across all field sites, and

408 reports are often perceived as being mishandled or dismissed.

409 These findings highlight a need for special consideration of risk during long-term fieldwork,

410 and for policies and protocols to not only be in place and communicated to participants before they

411 leave for site, but also reiterated intermittently throughout the fieldwork period. Site leaders must

412 ensure that behavioural expectations, and the consequences for not abiding by these expectations, are

413 made explicit to all participants and enforced where necessary. 
415 Fieldwork: a high-risk environment for marginalised identities?

The results of our study show that individuals who are part of some traditionally marginalised

417 identities are at higher risk of experiencing sexual misconduct during fieldwork than those not part of

418 that identity. Minority groups face higher risks of experiencing sexual misconduct in academia

419 generally (National Union of Students 2018), and also in fieldwork specifically (Clancy, Nelson,

420 Rutherford and Hinde 2014; Voss 2021a). If fieldwork is to continue to be a core area of knowledge

421 production in our disciplines, we must ensure that this arena is safe for all our colleagues.

We found significant associations between identifying as non-male and as a sexual minority

423 (i.e. gay, lesbian and bisexual) and experiencing misconduct. Due to small sample sizes, previous

424 quantitative studies (e.g. Clancy, Nelson, Rutherford and Hinde 2014) have been unable to identify

425 such pattern and capture the experiences of LGBTQ+ individuals. Ours is the first to fill this gap, with

$42626 \%$ of our participants identifying as a sexual minority ${ }^{2}(n=78)$.

Sexual minority participants were specifically more likely to experience sexual harassment

428 and sexual assault, whilst rates of experiencing rape were minimally different between heterosexual

429 and sexual minority participants. $40.91 \%(n=27 / 66)$ of sexual minority participants experienced

430 sexual harassment compared to $21.64 \%(n=29 / 134)$ of heterosexual participants. $12.12 \%(n=8 / 66)$ of

431 sexual minority participants experienced sexual assault, compared to $8.96 \%(n=12 / 134)$ of

432 heterosexual participants. Sexual harassment may partly be higher in sexual minority participants due

433 to the fact that homophobic attacks can also be sexualized. For example, Voss (2021a, 247) wrote

434 about experiencing sexaulised homophobia during fieldwork, such as being asked "How do you know

435 you're really a lesbian if you haven't slept with me [a man] yet?". In our study, one participant wrote

436 about their experience, stating that "almost any interaction with [the perpetrator] was offensive,

437 homophobic, or sexualised and [the perpetrator] was worse if [they] had been drinking”. Another

438 participant spoke about being a bystander to this kind of sexualized homophobia, writing "I remember

\footnotetext{
${ }^{2}$ We use this term to differentiate between when we are discussing the LGBTQ+ community as a whole, such as when other papers have done so, and when we are speaking specifically about our results and dataset, within which we do not have a large enough sample size to speak to the experiences of transgender individuals.
} 
439 this girl at the [field] that was openly lesbian [...] There were jokes all the time about it, some of them

440 can be described as sexual harassment, that I can tell now that did not make her feel ok. Some of us

441 never participated [...] because we knew she could feel bad, but nobody was able to ask them to

442 stop."

443 Fieldwork may also be a high-risk environment in regard to the scale of the potential impact

444 of experiencing sexual misconduct. Fieldwork is not necessarily unique in its risk of sexual

445 misconduct occurring; however, the impact of experiencing sexual misconduct may be amplified by

446 the nature of fieldwork. Nelson et al (2017) found that professional opportunities were withheld from

447 victims, as well as resources such as food, water and access to urination breaks during fieldwork, and

448 participants were concerned that negative experiences in the field could have serious career

449 implications. Johansson (2015) wrote about their experiences as a lone-researcher carrying out

450 anthropological fieldwork, sharing that informants would demand sexual acts in return for

451 information. When Johansson outright rejected these advances, there were negative implications for

452 their research. Heath-Stout (2019) found through qualitative interviews that many interviewees left

453 field projects and research fields to avoid perpetrators.

454 The results of this study, however, are unable to speak to the experiences of ethnic minorities, 455 transgender individuals, and disabled individuals. These demographics were underrepresented in our 456 data set, with only $6 . \%(n=20 / 300)$ of participants identifying as an ethnic minority, $1 \%(n=3 / 100)$ as 457 transgender, and $9.00 \%(\mathrm{n}=27 / 300)$ as disabled. Whilst we found no significant association between 458 participants who identified as an ethnic minority and experiencing sexual misconduct, this is 459 contradictory to previous studies that have identified that students of colour - and particularly women 460 of colour - experience misconduct at higher rates (Cantalupo 2018). Similarly, our model did not

461 identify any significant associations between identifying as disabled and experiencing sexual 462 misconduct. Yet, a US National Crime Victimisation Survey (Harrell 2015) found that the rate of 463 violent crime experienced by disabled individuals (including rape and sexual assault) was 36 people 464 per 1000, compared to 14 per 1000 for non-disabled individuals. The disparity been our results and 465 previous literature may be due to our small sample sizes for these demographics. 
467 by the under-representation of people of colour, and particularly women of colour, in STEM subjects

468 (Towns 2010). It is also important to note that a participant may be Black, Indigenous and/or a person 469 of colour but not identify as an ethnic minority. The wording of the survey question did not allow for 470 the complexities of self-identification and how that may change through time and space, and thus 471 conclusions should not be drawn about the experiences of different ethnicities from this data. Further 472 research is required to draw any solid conclusions about the experiences of disabled individuals and 473 ethnic minorities in our fields. A survey specifically designed to look at the interactions between 474 sexual misconduct and disability, and sexual misconduct and ethnicity, may yield different results.

475 Given the lack of representation of these groups in all existing studies on fieldwork sexual 476 misconduct, this should be an urgent priority for future research. 


\section{Conclusions}

This research fills two major gaps in the study of sexual misconduct during fieldwork. Firstly,

482 and to the best of the authors knowledge, we were able to assess the experiences of sexual minority

483 colleagues undertaking fieldwork. Our research confirms that, as in other contexts (e.g. Department of

484 the Interior 2017; National Park Service 2017; National Union of Students 2018), sexual minority

485 individuals undertaking fieldwork are more likely to experience sexual misconduct than their

486 heterosexual peers. The sexual misconduct experienced by sexual minority fieldworkers within our

487 sample also often included homophobic harassment.

Secondly, this is the first quantitative study able to identify specific risk factors for the

489 occurrence of sexual misconduct in fieldwork. The existence of policies and protocols specifically

490 relating to sexual misconduct decreased the risk of sexual misconduct occurring; participants who

491 knew about policies and protocols relating to sexual misconduct before arriving on site were

492 significantly less likely to report experiencing misconduct. Furthermore, as the length of fieldwork

493 increased, so did the risk of participants experiencing sexual misconduct. We propose that rather than

494 this being due to greater opportunity for misconduct to occur on longer fieldwork projects, that this is

495 actually due to other risk factors, such as a culture of tolerance for sexual misconduct (also found to

496 correlate with sexual harassment in other contexts, e.g. Department of the Interior 2017 and National

497 Park Service 2017) and frequent alcohol consumption (found to correlate with sexual misconduct in

498 other contexts, e.g. Abbey et al 2001 and Bacharach, Bamberger and McKinney 2007), creating a

499 cumulative effect that grows over time resulting in potential perpetrators viewing (consciously or

500 unconsciously) fieldwork as an environment in which there is low-risk of consequences. Additionally,

501 the very policies and protocols that are needed to signal a zero-tolerance approach to sexual

502 misconduct are lacking and inconsistent across field sites (also found by Nelson et al 2017), and when

503 reports were made these were often minimised or mishandled within our data set.

An awareness of these factors can be used to inform and create evidence-based policies,

505 protocols, and risk-assessments for field sites and fieldwork. It is important to note that the mitigation

506 strategy for the increased risk to minority individuals within fieldwork cannot be to discourage these 
507 individuals from partaking in fieldwork or create additional barriers for participation, nor can the

508 strategy for mitigating the risk of length be to limit the length of fieldwork. Instead, we propose that

509 policies and protocols specifically aimed to tackle sexual misconduct should be seen as an integral

510 part of fieldwork planning. Further research investigating different types of policies surrounding

511 sexual misconduct and their effectiveness during fieldwork is of imminent importance. This paper

512 measured absence/presence of policies and protocols on fieldsites, and participants knowledge of

513 these policies. It is possible that, given inclusion of policies related to sexual misconduct are not

514 universal on fieldsites nor even necessarily common, the field-sites within our sample that did include

515 these policies were also discouraging misconduct and fostering a safer culture in other unmeasured

516 ways. Further in-depth research would help clarify this.

517 Given that we received responses from individuals who partook in many different types of

518 fieldwork — from lone-working, to established field schools — we believe these results are generally

519 applicable to a range of different field working contexts, and potentially to a range of different

520 disciplines outside of archaeology and anthropology.

521 We conclude that there are specific social and environmental variables present in fieldwork

522 that predict the occurrence of sexual misconduct. Fieldwork is a low-risk environment in terms of

523 consequences for perpetrators, and a high-risk environment in terms of experiencing sexual

524 misconduct for some traditionally marginalised groups. These in combination create an environment

525 in which, if left unchecked, sexual misconduct can thrive.

526 Sexual misconduct poses a significant threat to both the safety and welfare of our colleagues,

527 and also to our discipline and the research we create. Those who experience misconduct are known to

528 change career paths or leave their positions entirely (Chan, Chow, Lam and Cheung 2008; Clancy,

529 Nelson, Rutherford and Hinde 2014; Lim and Cortina 2005; Meyers et al 2018; Nelson et al 2017),

530 resulting in a significant loss of potential talent. Furthermore, our research confirms that members of

531 some minority groups are significantly more likely to experience misconduct, which could lead to a

532 particular loss of diverse researchers. In order to combat this and protect fieldwork as a key area of

533 knowledge production, policies and protocols that are evidence-based and aimed at mitigating the risk

534 of sexual misconduct must be implemented and communicated clearly across all field sites. They must 
535 also be reiterated intermittently throughout the field season and must take into consideration factors

536 such as alcohol consumption, and that workers are often working, living, and socialising together

537 throughout this time period.

538 

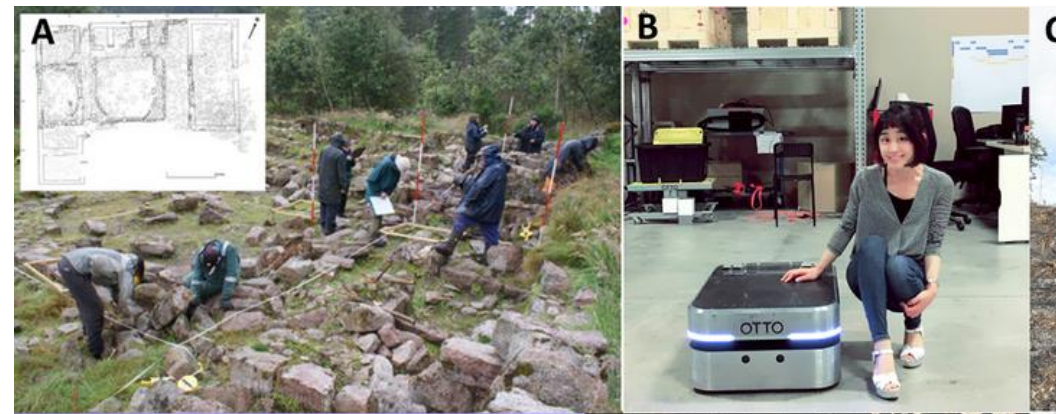

C

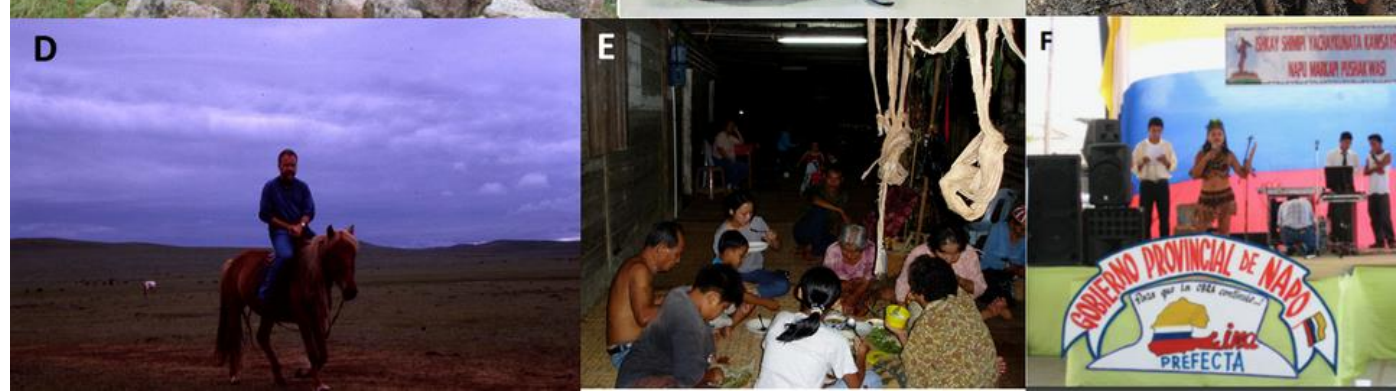

Figure 1. Photographs showcasing the variation of fieldwork types. Panel A: A photo of a

541 community archaeology project in Scotland involving volunteers (@) Oliver et al 2016; used with

542 permission). Panel B: An anthropologist at a robotics company in North America, where she

543 visited for 3 weeks collecting ethnographic data (@ Chun and Knight 2020; used with

544 permission). Panel C: An anthropologist planting rice at their fieldsite (@ Liana Chua; used with

545 permission). Panel D: An anthropologist on horseback during fieldwork in Mongolia, 1999 (C)

546 Christopher Kaplonski; used with permission). Panel E: An anthropologist eating with members

547 of the local community during a ritual (@ Liana Chua; used with permission). Panel F: A photo

548 taken by an anthropologist at a Kichwa discourse contest in Tena (@) Wroblewski 2019; used with

549 permission). 


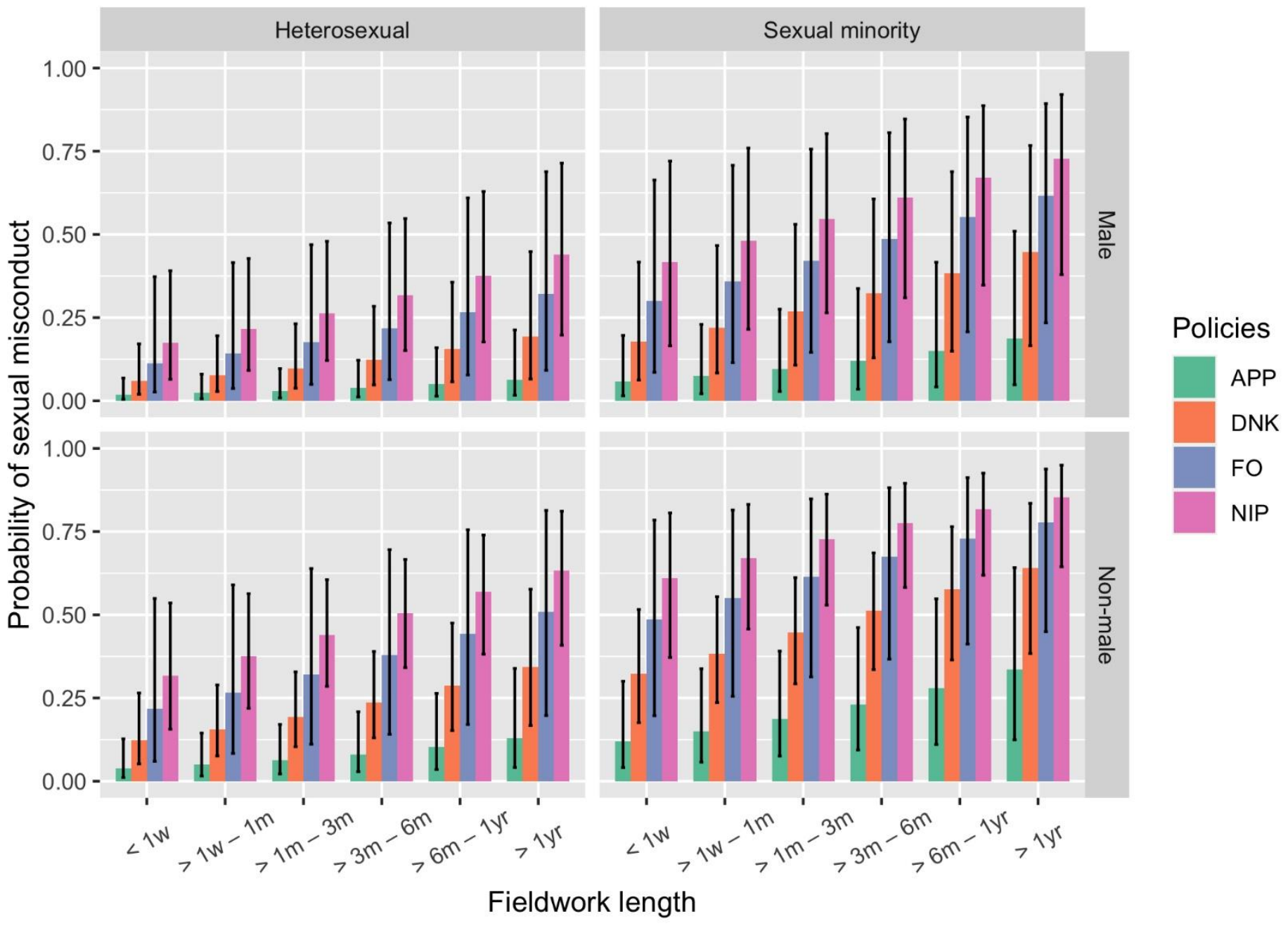




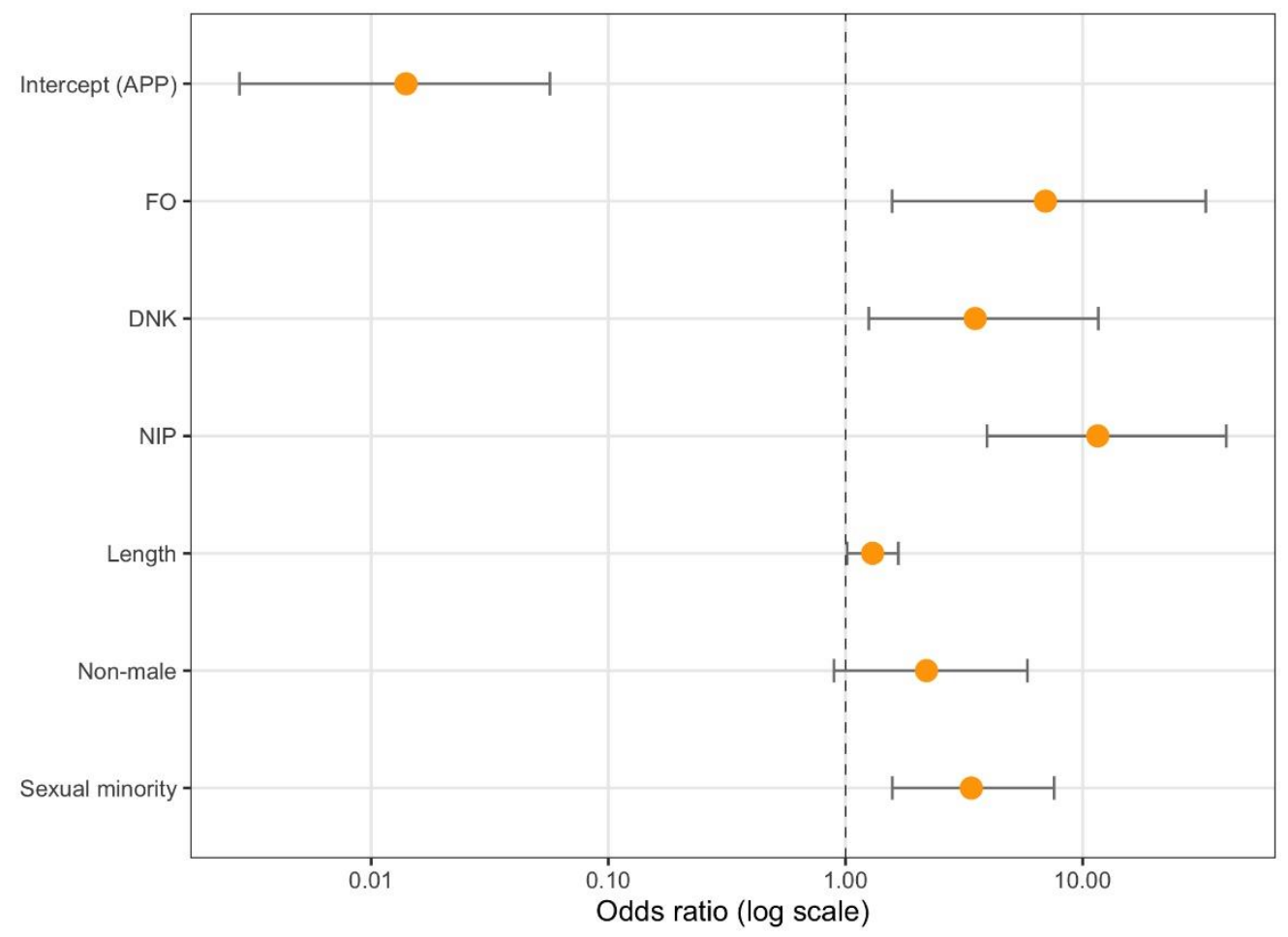

Figure 3. Counter-factual plot showing model prediction for sexual misconduct.

557 


\begin{tabular}{|c|c|c|c|c|}
\hline Variable name & Survey question & Raw categories & Levels & Variable type \\
\hline $\begin{array}{l}\text { Sexual } \\
\text { harassment } \\
\text { policies }\end{array}$ & $\begin{array}{l}\text { Were you aware of the policies and protocols } \\
\text { regarding the possibility of sexual misconduct } \\
\text { in the field for this [your most recent] site? }\end{array}$ & $\begin{array}{l}\text { Yes, I was aware of policies and protocols before I went; } \\
\text { Yes, I found out about them whilst I was there; } \\
\text { No, if there were any in place I did not know about them; } \\
\text { No, there were no policies or protocols in place }\end{array}$ & $\begin{array}{c}\text { APP; } \\
\text { FO; } \\
\text { DNK; } \\
\text { NIP }\end{array}$ & Factor \\
\hline $\begin{array}{l}\text { Length of } \\
\text { fieldwork }\end{array}$ & $\begin{array}{l}\text { How long were you partaking in [your most } \\
\text { recent experience of] fieldwork for } \\
\text { consecutively? }\end{array}$ & $\begin{array}{l}<1 \text { week; } \\
>1 \text { week }-1 \text { month; } \\
>1 \text { month }-3 \text { months; } \\
>3 \text { months }-6 \text { months; } \\
>6 \text { months }-1 \text { year; } \\
>1 \text { year }\end{array}$ & $\begin{array}{l}1 ; \\
2 ; \\
3 ; \\
4 ; \\
5 ; \\
6\end{array}$ & Numeric \\
\hline Gender & How would you identify your gender identity? & $\begin{array}{l}\text { Male; } \\
\text { Female; } \\
\text { Non-binary; } \\
\text { Prefer not to say }\end{array}$ & $\begin{array}{c}\text { Male; } \\
\text { Non-Male }\end{array}$ & Factor \\
\hline Sexuality & How would you define your sexual orientation? & $\begin{array}{l}\text { Heterosexual; Homosexual; } \\
\text { Bisexual; Asexual; } \\
\text { Other (please specify); Prefer not to say }\end{array}$ & $\begin{array}{l}\text { Heterosexual; } \\
\text { Sexual } \\
\text { minority }\end{array}$ & Factor \\
\hline Frequency & $\begin{array}{l}\text { Have you ever experienced any of the } \\
\text { following in the workplace (including } \\
\text { fieldwork and non-fieldwork contexts)? Please } \\
\text { tick all that apply. }\end{array}$ & $\begin{array}{l}\text { [List of example experiences that fall under the legal } \\
\text { definitions of sexual harassment or assault; see } \\
\text { Supplementary materials } 1 \text { for full list] }\end{array}$ & $\begin{array}{l}\text { True; } \\
\text { False }\end{array}$ & Factor \\
\hline
\end{tabular}

559 Table 1. Table showing the variables used in the GLM, with the survey questions the variable came from, the raw categories, and the coded categories. 


\section{Notes}

Acknowledgements. We would like to thank Dr Tiffany Page and Dr Dacia Viejo Rose for their help, guidance, and input during the initial stages of this project. We would also like to thank the anonymous reviewers who gave such thoughtful and thorough feedback on the manuscript. Finally, we would like to thank the participants who were involved in this study and without whom this manuscript would not be possible. 


\section{References}

Abbey, A., Zawacki, T., Buck, P., Clinton, A. and McAuslan, P. 2001. "Alcohol and sexual assault." Alcohol Research \& Health, 25(1):43-51.

Alriksson-Schmidt, Ann., Armour, Brian., Thibadeau, Judy. 2010. “Are adolescent girls with a physical disability at increased risk for sexual violence?”. Journal of School Health 80, no. 7: 361-367. doi:10.1111/j.1746-1561.2010.00514.x

Bacharach, Samuel., Bamberger, Peter. and McKinney, Valerie. 2007. "Harassing under the influence: The prevalence of male heavy drinking, the embeddedness of permissive workplace drinking norms, and the gender harassment of female coworkers.” Journal of Occupational Health Psychology, 12(3):232-250.

Berdahl, Jennifer L., and Celia Moore. 2006. "Workplace Harassment: Double Jeopardy For Minority Women." Journal Of Applied Psychology 91 (2): 426-436. doi:10.1037/0021-9010.91.2.426.

Biernacki, Patrick, and Dan Waldorf. 1981. "Snowball Sampling: Problems And Techniques Of Chain Referral Sampling." Sociological Methods \& Research 10 (2): 141-163.

doi:10.1177/004912418101000205.

Cantalupo, Nancy Chi. 2019. "And Even More Of Us Are Brave: Intersectionality \& Sexual Harassment Of Women Students Of Color". Harvard Journal Of Law And Gender.

Chamberlain, Lindsey Joyce, Martha Crowley, Daniel Tope, and Randy Hodson. 2008. "Sexual Harassment In Organizational Context". Work And Occupations 35 (3): 262-295. doi:10.1177/0730888408322008. 
Chan, Darius K-S, Suk Yee Chow, Chun Bun Lam, and Shu Fai Cheung. 2008. "Examining The JobRelated, Psychological, And Physical Outcomes Of Workplace Sexual Harassment: A Meta-Analytic Review". Psychology Of Women Quarterly 32 (4): 362-376. doi:10.1111/j.1471-6402.2008.00451.x.

Chun, Bohkyung, and Heather Knight. 2020. "The Robot Makers". ACM Transactions On Human-Robot Interaction 9 (3): 1-36. doi:10.1145/3377343.

Citizens Advice. n.d.a "Sexual Harassment". Accessed October 102018.

https://www.citizensadvice.org.uk/law-and-courts/discrimination/what-are-the-different-types-ofdiscrimination/sexual-harassment/.

Citizens Advice. n.d.b "Rape and Sexual Assault". Accessed October 102018. https://www.citizensadvice.org.uk/family/gender-violence/rape-and-sexual-assault/.

Clancy, Kathryn B. H., Nelson, Robin., Rutherford Julienne N. and Hinde, Katie. 2014. "Survey Of Academic Field Experiences (SAFE): Trainees Report Harassment And Assault". Plos ONE 9 (7): e102172. doi:10.1371/journal.pone.0102172.

Colaninno, Carol E., Lambert, Shawn P., Beahm, Emily L., and Drexler, Carl G. 2020. "Creating And Supporting A Harassment- And Assault-Free Field School". Advances In Archaeological Practice 8 (2): 111-122. doi:10.1017/aap.2020.8.

Department of the Interior, 2017. Work Environment Survey January-March 2017. [online] Available at: <https://www.doi.gov/sites/doi.gov/files/uploads/doi_wes_technical_report.pdf> [Accessed 3 January 2022]. 
Frye, Jocelyn. 2017. "Not Just the Rice and Famous: The Pervasiveness of Sexual Harassment Across

Industries Affects All Workers." The Centre for American Progress website. Accessed 11/12/2021.

https://www.americanprogress.org/article/not-just-rich-famous/

Hagen, Richard. 1979. The Bio-Sexual Factor. Garden City, N.Y.: Doubleday.

Heath-Stout, Laura Ellen. 2019. Diversity, Identity, and Oppression in the Production of Archaeological Knowledge. PhD dissertation, Department of Anthropology, Boston University, Boston.

Ilies, Remus., Hauserman, Nancy., Schwochau, Susan., Stibal, John. 2003. "Reported incidence rates of work-related sexual harassment in the United States: Using meta-analysis to explain reported rate disparities.” Personnel Psychology 56: 607-631. doi:10.1111/j.1744-6570.2003.tb00752.x

Johansson, Leanne. 2015. “Dangerous liaisons: Risk, positionality and power in women’s anthropological fieldwork. " Journal of the Anthropological Society of Oxford 7(1): 55-63. doi: 10.1.1.724.3068

Kloß, Sinah Theres. 2016. "Sexual(Ized) Harassment And Ethnographic Fieldwork: A Silenced Aspect Of Social Research". Ethnography 18 (3): 396-414. doi:10.1177/1466138116641958.

Langham, Ian. 1981. The Building Of British Social Anthropology. Springer Netherlands. 
Leighton, Mary. 2020. "Myths Of Meritocracy, Friendship, And Fun Work: Class And Gender In North American Academic Communities". American Anthropologist 122 (3): 444-458.

doi:10.1111/aman.13455.

Lim, Sandy, and Cortina, Lilia M.. 2005. "Interpersonal Mistreatment In The Workplace: The Interface And Impact Of General Incivility And Sexual Harassment.". Journal Of Applied Psychology 90 (3): 483496. doi:10.1037/0021-9010.90.3.483.

McCann, Deirdre. 2005. "Sexual Harassment At Work: National And International Responses, Conditions Of Work And Employment Series No. 2". International Labour Organisation.

McDonald, Paula. 2011. "Workplace Sexual Harassment 30 Years On: A Review Of The Literature". International Journal Of Management Reviews 14 (1): 1-17. doi:10.1111/j.1468-2370.2011.00300.x.

Moser, Stephanie. 2007. "On Disciplinary Culture: Archaeology As Fieldwork And Its Gendered Associations". Journal Of Archaeological Method And Theory 14 (3): 235-263. doi:10.1007/s10816-0079033-5.

National Park Service, 2017. Work Environment Survey January-March 2017. [online] Available at: <https://www.nps.gov/aboutus/upload/NPS-WES-Technical-Report-20170929-Accessible.pdf> [Accessed 3 January 2022].

National Union of Students. 2018. "Power In The Academy: Staff Sexual Misconduct In UK Higher Education.". https://www.nusconnect.org.uk/resources/nus-staff-student-sexual-misconduct-report. 
Nelson, Robin G., Rutherford, Julienne N., Hinde, Katie., and Clancy, Kathryn B. H. 2017. "Signaling Safety: Characterizing Fieldwork Experiences And Their Implications For Career Trajectories". American Anthropologist 119 (4): 710-722. doi:10.1111/aman.12929.

Oliver, Jeff, Jackson Armstrong, Karen Milek, J. Edward Schofield, Jo Vergunst, Thomas Brochard, Aoife Gould, and Gordon Noble. 2016. "The Bennachie Colony: A Nineteenth-Century Informal Community In Northeast Scotland". International Journal Of Historical Archaeology 20 (2): 341-377. doi:10.1007/s10761-016-0336-7.

Pollard, Amy. 2009. "Field Of Screams: Difficulty And Ethnographic Fieldwork". Anthropology Matters 11 (2). doi:10.22582/am.v11i2.10.

Rosenthal, Marina, and Jennifer Freyd. 2018. "Sexual Violence On Campus: No Evidence That Studies Are Biased Due To Self-Selection". Dignity: A Journal On Sexual Exploitation And Violence 3 (1). doi:10.23860/dignity.2018.03.01.07.

Sharp, Gwen, and Kremer, Emily. 2006. "4. The Safety Dance: Confronting Harassment, Intimidation, And Violence In The Field". Sociological Methodology 36 (1): 317-327. doi:10.1111/j.14679531.2006.00183.x.

Symons, Donald. 1981. The Evolution Of Human Sexuality. Oxford: Oxford University Press.

Towns, Marcy H. 2010. "Where Are The Women Of Color? Data On African American, Hispanic, And Native American Faculty In STEM.". Journal Of College Science Teaching. 
Vandermassen, Griet. 2010. "Evolution And Rape: A Feminist Darwinian Perspective". Sex Roles 64 (910): 732-747. doi:10.1007/s11199-010-9895-y.

Voss, Barbara. 2021a. "Documenting Cultures of Harassment in Archaeology: A Review and Analysis of Quantitative and Qualitative Research Studies.” American Antiquity, 1-17. doi:10.1017/aaq.2020.118

Voss, Barbara. 2021b. "Disrupting Cultures of Harassment in Archaeology: Social-Environmental and Trauma-Informed Approaches to Disciplinary Transformation.” American Antiquity, 1-18. doi:10.1017/aaq.2021.19

Wroblewski, Michael. 2019. "Performing Pluralism: Language, Indigeneity, And Ritual Activism In Amazonia". The Journal Of Latin American And Caribbean Anthropology 24 (1): 181-202. doi:10.1111/jlca.12387. 
Supplementary materials 1: Other measured variables.

Table 3. Table showing the variable name, levels, raw percentage of those who experienced sexual misconduct, the statistical test, the adjusted P-Value, the df and the X-squared for the other measured variables. P-Values were adjusted using Bonferroni correction to control for multiplehypothesis testing. 


\begin{tabular}{|c|c|c|c|c|c|c|}
\hline Variable name & Levels & $\begin{array}{c}\text { Percentage who experienced sexual } \\
\text { harassment and/or assault }\end{array}$ & Test & $\begin{array}{l}\text { Adjusted P- } \\
\text { value }\end{array}$ & df & $\mathrm{X}$-squared \\
\hline \multirow[t]{3}{*}{ Fieldwork type } & Field school & $21.28 \%(\mathrm{~N}=10 / 47)$ & & 0.13286 & 2 & 7.9286 \\
\hline & Field site & $28.10 \%(\mathrm{~N}=34 / 121)$ & Chi-square & & & \\
\hline & Lone-working & $55.00 \%(\mathrm{~N}=11 / 20)$ & & & & \\
\hline \multirow[t]{2}{*}{ Accommodation } & Shared accommodation & $26.61 \%(\mathrm{~N}=33 / 124)$ & & 1 & & \\
\hline & Private accommodation & $30.19 \%(\mathrm{~N}=16 / 53)$ & Chi-square & & 1 & 0.092161 \\
\hline \multirow[t]{2}{*}{ Gender of PI } & Male & $27.27 \%(\mathrm{~N}=36 / 132)$ & Chi-square & 1 & 1 & $6.7496 e-31$ \\
\hline & Female & $27.94 \%(\mathrm{~N}=19 / 68)$ & & & & \\
\hline \multirow{3}{*}{$\begin{array}{l}\text { Ratio of male:female } \\
\text { participants }\end{array}$} & About the same & $26.67 \%(\mathrm{~N}=24 / 90)$ & Chi-square & 1 & 2 & 0.085044 \\
\hline & More men than women & $28.95 \%(\mathrm{~N}=11 / 38)$ & & & & \\
\hline & More women than men & $28.17 \%(\mathrm{~N}=20 / 71)$ & & & & \\
\hline \multirow[t]{2}{*}{ Division of labour } & Work equally assigned & $24.07 \%(\mathrm{~N}=39 / 162)$ & Chi-square & 0.60249 & 1 & 2.9464 \\
\hline & $\begin{array}{l}\text { Work assigned differently } \\
\text { based on gender }\end{array}$ & $40.00 \%(\mathrm{~N}=14 / 35)$ & & & & \\
\hline \multirow[t]{2}{*}{ Location } & Abroad & $28.83 \%(\mathrm{~N}=32 / 111)$ & Chi-square & 1 & 1 & $3.4466 \mathrm{e}-30$ \\
\hline & Not abroad & $28.72 \%(\mathrm{~N}=27 / 94)$ & & & & \\
\hline \multirow[t]{2}{*}{ Language } & Fluent in local language & $30.43 \%(\mathrm{~N}=35 / 115)$ & Chi-square & 1 & 1 & 0.096277 \\
\hline & Was not fluent & $27.38 \%(\mathrm{~N}=23 / 84)$ & & & & \\
\hline
\end{tabular}


As well as participant demographics (gender identity, sexuality, disability status and ethnic minority identity) and the two environmental variables discussed above (length of fieldwork and policies and protocols), we measured a number of other variables and their potential impact on the occurrence of sexual misconduct within our dataset. We analysed these variables using Chi-square tests, and used Bonferroni correction to control for multiple-hypothesis testing.

Previous papers (e.g. Colaninno, Lambert, Beahm and Drexler 2020) have hypothesised that a male-dominated workplace within fieldwork specifically may contribute to the occurrence of sexual misconduct. We measured three related variables: the gender of the PI, the ratio of male to female participants, and whether or not there was a perceived gendered division of labour on the fieldsite. As shown in Table 3, none of these variables had a statistically significant effect on whether or not a participant had experienced sexual misconduct.

We also measured the type of fieldwork, the type of accommodation, the location of the fieldsite, and whether or not the participant spoke the local language. None of these variables were significant.

Supplementary materials 2: Full list of survey questions, with non-question text that was in the survey to guide respondents italicised and page breaks, open box questions and other important information indicated in square brackets.

All of these points are required. If you do not consent to all of the points, please do not continue with the survey.

1. I can confirm that I have read and understood the 'Information for potential participants page'

\section{Yes}

2. I understand that I will be able to withdraw my data by contacting the main researcher using a unique identifying word anytime up until publication.

1. Yes 
3. I voluntarily agree to take part in this survey.

1. Yes

4. I consent to the processing of my personal information. I understand that such information istepiwill be handled in accordance with all applicable data protection legislation.

1. Yes

5. I understand that all personal information will remain confidential and that all efforts will be made to ensure I cannot be identified.

1. Yes

6. I agree that my anonymised research data may be used by others for future research, and understand that no-one will be able to identify me when this data is shared.

1. Yes

7. I know who to contact if I wish to ask any questions or lodge a complaint

1. Yes

[Page break]

1. How would you identify your gender identity?

1. Female

2. Male

3. Non-binary

4. Prefer not to say

2. Do you identity with the gender you were assigned at birth?

1. Yes 
2. No

3. Prefer not to say

3. How would you define your sexual orientation?

1. Heterosexual

2. Homosexual

3. Bisexual

4. Asexual

5. Other (please specify)

6. Prefer not to say

4. Do you identify as being disabled?

1. Yes

2. No

3. Prefer not to say

5. Do you identify as an ethic minority?

1. Yes

2. No

3. Prefer not to say

6. Country of origin

1. [Open box]

[Page break] 
Please think back to your most recent archaeological or anthropological fieldwork experience and answer the following questions.

1. How old were you?

1. $<18$

2. $18-20$

3. $21-25$

4. $26-30$

5. $31-35$

6. $36-40$

7. $41-45$

8. $46-50$

9. $51-55$

10. $56-60$

11. $61-65$

12. $>65$

2. What was the highest level of education you had completed?

1. High school/A-Levels

2. Undergraduate

3. Masters

4. $\mathrm{PhD}$

5. Other (please specify)

3. What type of fieldwork were you partaking in?

1. Lone-working

2. Field site

3. Field school

4. Other (please specify)

4. How long were you partaking in the fieldwork for consecutively?

1. <1week

2. $>1$ week-1month

3. >1month-3months

4. > 3 months -6 months

5. >6months-1year

6. >1year

5. What best describe your accommodation?

1. Private accommodation, living alone

2. Living with those part of your project, in the same residence

3. Other (please specify) 
6. How many people were part of the field site?

1. Just myself

2. $1-5$

3. $6-10$

4. $11+$

7. Was the head/director of the site or PI...

1. Male

2. Female

8. At the field site, did you feel that the division of labour was based on gender?

1. Yes, there were definitely differences in work assigned to men vs women

2. No, all work was assigned equally or based on other attributes and gender did not impact on this (such as seniority, experience, etc)

9. Did you feel free and able to leave the site at any time, if necessary?

1. Yes

2. No

10. Was the site in another country?

1. Yes

2. No

11. Had you been to that country before?

1. Yes

2. No

12. Did you speak the language of the country you were working in?

1. Yes, I was fluent in the local language

2. No, I didn't know the language at all

3. I knew enough to get by on my own

4. I knew some, but often relied on others who were more fluent to get by

13. Were you aware of the policies and protocols regarding the possibility of sexual misconduct in the field for this site?

1. Yes, I was aware of policies and protocols before I went

2. Yes, I found out about them whilst I was there

3. No, if there were any in place I didn't know about them

4. No, there were no polices or protocols in place

14. To what extent did you feel safe and able to carry out your work to the best of your abilities whilst there?

1. [Sliding scale, $0-100$ with $0=$ not at all and $100=$ completely] 
15. Did you experience any of the following during your most recent fieldwork experience? Please tick all that apply. Please note that consent is defined by agreeing by choice and having the freedom and capacity to make that choice. Therefore, 'consent' given under coercion, fear, or whilst not able physically and/or mentally to give that consent does not count as consent.

1. Someone else sharing intimate details with you that made you feel intimidated, uncomfortable, or humiliated

2. Someone else drawing you into a discussion about sex that made you feel intimidated, uncomfortable, or humiliated

3. Someone else making sexualised comments towards you that made you feel intimidated, uncomfortable, or humiliated

4. Someone else asking, hinting, or suggesting sex to you in a way that made you feel intimidated, uncomfortable, or humiliated

5. Someone else sending you explicit or sexualise messages that made you feel intimidated, uncomfortable, or humiliated

6. Someone else touching you non-consensually in a sexualised manner

7. Someone else initiating non-consensual sexual contact towards you

8. Someone else subjecting you to non-consensual penetration (including any body part or object)

9. No, I did not experience any of the above

[Page break]

1. Have you ever experienced any of the following in the workplace (including fieldwork and nonfieldwork contexts)? Please tick all that apply. Please note that consent is defined by agreeing by choice and having the freedom and capacity to make that choice. Therefore, 'consent' given under coercion, fear, or whilst not able physically and/or mentally to give that consent does not count as consent.

1. Someone else sharing intimate details with you that made you feel intimidated, uncomfortable, or humiliated

2. Someone else drawing you into a discussion about sex that made you feel intimidated, uncomfortable, or humiliated

3. Someone else making sexualised comments towards you that made you feel intimidated, uncomfortable, or humiliated

4. Someone else asking, hinting, or suggesting sex to you in a way that made you feel intimidated, uncomfortable, or humiliated 
5. Someone else sending you explicit or sexualise messages that made you feel intimidated, uncomfortable, or humiliated

6. Someone else touching you non-consensually in a sexualised manner

7. Someone else initiating non-consensual sexual contact towards you

8. Someone else subjecting you to non-consensual penetration (including any body part or object)

9. No, I did not experience any of the above

2. If yes, where have you experienced these?

1. During fieldwork

2. In another workplace context, not fieldwork

3. Both

[Page break]

If you have experienced any of the scenarios listed in the previous question, please think back to your most recent experience. If you have never experienced any of these, please skip this question.

1. Which of these occurred during your most recent experience? If more than one was part of the same event, please tick all that apply.

1. Someone else sharing intimate details with you that made you feel intimidated, uncomfortable, or humiliated

2. Someone else drawing you into a discussion about sex that made you feel intimidated, uncomfortable, or humiliated

3. Someone else making sexualised comments towards you that made you feel intimidated, uncomfortable, or humiliated

4. Someone else asking, hinting, or suggesting sex to you in a way that made you feel intimidated, uncomfortable, or humiliated

5. Someone else sending you explicit or sexualise messages that made you feel intimidated, uncomfortable, or humiliated

6. Someone else touching you non-consensually in a sexualised manner

7. Someone else initiating non-consensual sexual contact towards you

8. Someone else subjecting you to non-consensual penetration (including any body part or object)

2. Did this take place in fieldwork or a non-fieldwork workplace setting

1. Fieldwork 


\section{Non-Fieldwork}

[Page break]

[If respondent selected 'non-fieldwork', redirected to this page]

1. What type of workplace setting did this occur in?

1. University/other educational institution

2. Lab work

3. Museum

4. Other (please specify)

2. How long ago did this occur?

1. In the past 6 months

2. > 6 months - a year ago

3. $>1$ year -2 years ago

4. $>2$ years -3 years ago

5. $>3$ years -4 years ago

6. $>4$ years -5 years ago

7. $>5$ years -6 years ago

8. $>6$ years -7 years ago

9. $>7$ years -8 years ago

10. $>8$ years -9 years ago

11. 10-15 years ago

3. How old were you?

1. $<18$

2. $18-20$

3. $21-25$

4. $26-30$

5. $31-35$

6. $36-40$

7. $41-45$

8. $46-50$

9. $51-55$ 
10. $56-60$

11. $61-65$

12. $>65$

4. What workplace position did you hold at the time? If you held more than one position at this time, please select all that applied.

1. Undergraduate student

2. Post-graduate student

3. Research position, not a student

4. Lecturer, professor, or supervisor (or equivalent)

5. Senior manager

6. Administrative staff

7. Other (please specify)

5. What was the gender of the perpetrator?

1. Male

2. Female

3. Non-binary

6. What was the seniority of the perpetrator in relation to yourself at that time?

1. More senior than me

2. The same seniority as me

3. Less senior than me

7. Were you aware of the policies and protocols regarding the possibility of sexual misconduct in the workplace?

1. Yes, I was aware of policies and protocols before I went

2. Yes, I found out about them whilst I was there

3. No, if there were any in place I didn't know about them

4. No, there were no polices or protocols in place

8. Did you report the event(s)?

1. Yes

2. No

9. If yes, did you feel the report was handled with sensitivity and the result was proportionate to the event(s)?

1. Yes

2. No

10. At the place of work connected to this event, did you witness any of the following? Please tick all that apply.

1. Bullying

2. Sexism

3. Racism 
4. Homophobia

5. Ableism

11. At the place of work connected to this event, did you experience any of the following? Please tick all that apply.

1. Bullying

2. Sexism

3. Racism

4. Homophobia

5. Ableism

[Page break]

[If respondent selected 'fieldwork', redirected to this page]

1. What type of fieldwork did this occur during?

1. Lone-working

2. Field school

3. Field site

4. Other (please specify)

2. How long ago did this occur?

1. In the past 6 months

2. > 6 months-a year ago

3. > 1 year -2 years ago

4. > 2 years -3 years ago

5. $>3$ years -4 years ago

6. > 4 years -5 years ago

7. $>5$ years -6 years ago

8. $>6$ years -7 years ago

9. $>7$ years -8 years ago

10. $>8$ years -9 years ago

11. 10-15 years ago

12. More than 15 years ago

3. How old were you? 
1. $<18$

2. $18-20$

3. $21-25$

4. 26-30

5. $31-35$

6. $36-40$

7. 41-45

8. $46-50$

9. 51-55

10. $56-60$

11. 61-65

12. $65+$

4. What workplace position did you hold at the time? If you held more than one position at this time, please select all that applied.

1. Undergraduate student

2. Post-graduate student

3. Research/field assistant

4. Senior manager, such as a supervisor, director, or PI (or equivalent)

5. A contracted (paid) fieldworker

6. Lone worker

7. Other (please specify)

5. What was the gender of the perpetrator?

1. Male

2. Female

3. Non-binary

6. What was the seniority of the perpetrator in relation to yourself at that time?

1. More senior than me

2. The same seniority as me

3. Less senior than me

7. How long were you partaking in the fieldwork for consecutively?

1. <1week

2. >1week-1month

3. >1month-3months

4. > 3 months -6 months

5. >6months-1year

6. >1year

8. What best describe your accommodation?

1. Private accommodation, living alone 
2. Living with those part of your project, in the same residence

3. Other (please specify)

9. How many people were part of the field site?

1. Just myself

2. $1-5$

3. $6-10$

4. $11+$

10. Was the head/director of the site or PI...

1. Male

2. Female

11. At the field site, did you feel that the division of labour was based on gender?

1. Yes, there were definitely differences in work assigned to men vs women

2. No, all work was assigned equally or based on other attributes and gender did not impact on this (such as seniority, experience, etc)

12. Did you feel free and able to leave the site at any time, if necessary?

1. Yes

2. No

13. Was the site in another country?

1. Yes

2. No

14. Had you been to that country before?

1. Yes

2. No

15. Did you speak the language of the country you were working in?

1. Yes, I was fluent in the local language

2. No, I didn't know the language at all

3. I knew enough to get by on my own

4. I knew some, but often relied on others who were more fluent to get by

16. Were you aware of the policies and protocols regarding the possibility of sexual misconduct in the field for this site?

1. Yes, I was aware of policies and protocols before I went

2. Yes, I found out about them whilst I was there

3. No, if there were any in place I didn't know about them

4. No, there were no polices or protocols in place

17. Did you report the event(s)?

1. Yes

2. No 
18. If yes, did you feel the report was handled with sensitivity and the result was proportionate to the event(s)?

1. Yes

2. No

19. Whilst taking part in the field work connected to this event, did you witness any of the following? Please tick all that apply.

1. Bullying

2. Sexism

3. Racism

4. Homophobia

5. Ableism

20. Whilst taking part in the field work connected to this event, did you experience any of the following? Please tick all that apply.
1. Bullying
2. Sexism
3. Racism
4. Homophobia
5. Ableism

[Page break]

1. In the space below, please add any other comments you feel relevant about your experiences in archaeology and/or anthropology. Please do not provide any identifying information about individuals, projects, field sites or institutions

\section{1. [Open box]}

2. Please leave a unique identifying word that can be used if you wish to withdraw your data any time up until $24^{\text {th }}$ April 2019.

\section{[Open box]}

